\title{
ANALISIS PENENTUAN PUSAT-PUSAT PERTUMBUHAN DAN KOMODITI BASIS PERTANIAN DI KABUPATEN PASAMAN
}

\section{Analysis of Determination of Growth Centers And Agricultural Commodities in Pasaman District}

\author{
Ananda Syahputra ${ }^{\text {* }}$, Yonariza $^{2}$, Hasnah $^{3}$ \\ ${ }^{1}$ Universitas Andalas, Padang, 25 163, Indonesia \\ ${ }^{2}$ Fakultas Pertanian, Padang, 25163, Indonesia \\ ${ }^{3}$ Program Studi Agribisnis, Pa dang, 25163, Indonesia \\ *email koresponden: sa lamkarya30@gmail.com
}

\begin{abstract}
Abstrak
Analisis penentuan pusat pertumbuhan wilayah dan komoditi basis merupakan upaya untuk mengoptimalkan pembangunan wilayah Kabupaten Pa saman. Penelitianinidapat dijadikan referensi kebijakan pembanguan bagi pemerintah Ka bupaten Pasaman. Tujuan penelitian iniuntuk mengidentifikasi kecamatan yang berpotensi sebagai pu sat pertumbuhan ekonomi dan men gidentifikasi komoditi pertanian basis masing-masing kecamatan Ka bupaten Pasaman serta mengidentifikasi interaksi antara pusatpertumbuhan (growth pole) dengan daerah sekitarnya (hinterland). Penelitian ini menggunakan tiga metode a nalisis da ta, y aitu a nalisis Skalogram, In deks Sentralitas, Location Quotient serta analisis Gra vitasi. Berdasarkan hasil analisis ska logram dan indeks sentralitas didapatkan bahwa dari 12 kecamatan y ang a da di Kabupaten Pasaman, teridentifikasi sebanyak 4 kecamatan sebagai pusat pertumbuhan. Empat kecamatan tersebut a dalah Keca matan Lubuk Sikaping dengan komoditi basis ikan sawah dan budidaya perairan umum, Ke camatan Rao Sela tan memiliki komiditi ba sis utama kangkung dan nenas, Kecamatan Panti memiliki komoditibasis ut a ma kelinci dan sapi potong, dan Kecamatan Tigo Na ga ri memiliki komoditi ba sis utama ikan sa wah dan ikan sungai. Pemerintah Kabu paten Pa sa man disarankan menetapkan kebijakan spesialisasi komoditi basis pa da masing-masing kecamatan dan memperkuat keterkaitan antar wilay ah, sehingga dapat mendorong pergerakan perekonomian secara merata.
\end{abstract}

Kata kunci: Pusat pertumbuhan, komoditibasis, interaksi

\section{Abstract}

Analysis of determining regional growth centers and basic commodities is an effort to optimize the regional development of Pasaman Regency. This research can be used as a reference for development policies for the Pasaman Regency government. The purpose of this research is to identifydistricts that have the potential to become centers of economic growth and to identify the basic agricultural commodities ofeach district of Pasaman Re gency and to identify the interactions between growth poles and the surrounding area (hinterland). This study uses three data analysis methods, namely Schalogramanalysis, Centrality Index, Location Quotientand Gravityanalysis. Based on the results of the schalogramanalysis and the centrality index, it was found that out of 12 sub-districts in Pasaman Regency, 4 subdistricts were identified as growth centers. The four sub-districts are Lubuk Sikaping District with the basic commodities of rice field fish and public water cultivation, South Rao District has the main base commodities of ka le and pineap ple, Panti District has the main base commodities of rabbits andbeefcattle, and Tigo Nagari District has the main base commodities of lowland fish and river fish. It is recommended that the Pasaman Regency government establish a policy of basic commodity specialization in each district and strengthen the inter-regional linkages, so as to encourage equ itable economic movement.

Keywords : Center of growth, commodities bases, interaction 


\section{PENDAHULUAN}

Pembangunan adalah rangkaian usaha perubahan yang dilakukan secara sadar oleh suatu bangsa, negara dan pemerintah dalam rangka pembinaan bangsa (S.P. Siagian, 2006:12). Menurut Haryono Sudiramunawar (2002) pembangunan diterjemahkan sebagai konsep perubahan sosial yang berlangsung terus menerus menuju kemajuan dan memerlukan masukan yang menyeluruh serta berkesinambungan. Target akhir dari kebijakan pembangunan adalah untuk mendongkrak pertumbuhan ekonomi dan kesejahteraan sosial secara merata (Syafrizal, 2008). Keberhasilan pembangunan nasional secara keseluruhan sangat ditentukan oleh keberhasilan pembangunan daerah. Kebijakan pada tingkat wilayah diperlukan karena kondisi permasalahan dan potensi pembangunan yang dimiliki suatu wilayah umumnya berbeda satu sama lainnya sehingga kebijakan yang diperlukan tidak sama (Todaro, 2009).

Hirschman dalam Todaro (1989), menyatakan bahwa untuk negara (daerah) yang berkembang, pembangunan ekonomi tidak dilakukan secara serentak (imbalanced growth) namun dilakukan dengan menetapkan sektor unggulan, dimana sektor unggulan ini akan memberi implikasi terhadap sektorsektor lainnya. Sedangkan menurut (Miyarto, Widyarti, \& Sugiyanto, 1993) dalam pembangunan ekonomi sektoral, prioritas hendaknya diberikan kepada sektor-sektor yang mempunyai daya penyebaran dan derajat kepekaan tinggi.

Pusat pertumbuhan ekonomi (growth pole) merupakan salah satu pendekatan pembangunan dalam upaya meningkatkan kesejahteraan masyarakat. Pertumbuhan ekonomi difokuskan pada daerah yang memiliki potensi tinggi dan fasilitas wilayah yang lebih memadai untuk mempercepat terjadinya persebaran kemajuan ekonomi. Sebab pertumbuhan suatu wilayah akan mempengaruhi wilayah di sekitarnya. Kemampuan pemerintah daerah untuk melihat sektor yang memiliki keunggulan/kelemahan di wilayahnya menjadi semakin penting. Sektor yang memiliki keunggulan, memiliki prospek yang lebih baik untuk dikembangkan dan diharapkan dapat mendorong sektor-sektor lain untuk berkembang. Oleh karena itu, diperlukan identifikasi terhadap sektor-sektor yang memiliki keunggulan tersebut.

Kabupaten Pasaman tergolong daerah relatif tertinggal. Dimana laju pertumbuhan Kabupaten Pasaman hanya senilai 5,78 persen. Nilai ini lebih rendah dibanding rata-rata kabupaten di Sumatera Barat yaitu 5,91 persen. Kabupaten Pasaman juga memiliki PDRB perkapita lebih rendah yaitu 22.523.753 rupiah. Nilai ini juga lebih rendah dibanding rata-rata Kabupaten di Sumatera Barat yaitu 28.016.941 rupiah. Oleh sebab itu diperlukan penentuan pusat-pusat pertumbuhan di Kabupaten Pasaman agar dapat memacu perkembangan wilayah sehingga terjadi pemerataan perekonomian pada setiap kecamatan. Penentuan pusat pertumbuhan wilayah sejalan dengan salah satu prioritas kebijakan pemerintah dalam Rencana Pembangunan Jangka Menengah Daerah (RPJMD) Kabupaten Pasaman 2016-2021, yaitu meningkatkan pendapatan dan perekonomian masyarakat yang berdaya saing dan mengoptimalkan pemanfaatan potensi sumber daya alam.

Dari seluruh sektor yang memberikan sumbangan dalam pembentukan PDRB Pasaman atas dasar harga berlaku, sektor pertanian merupakan andil terbesar yaitu 3.343.448,11 juta rupiah (2017) atau 41,53 persen dan tahun 2016 adalah 3.133.557,18 milyar rupiah atau 42,53 persen. Tiga sub sektor pertanian penyumbang PDRB terbesar bagi Kabupaten Pasaman adalah tanaman pangan yaitu $15,57 \%$, tanaman hortikultura tahunan yaiu $12,33 \%$, dan tanaman perkebunan tahunan yaitu 9,69 persen (BPS Pasaman, 2019) Supaya implementasi kebijakan pengembangan sektor pertanian mencapai optimal, maka perlu memilih prioritas pengembangan sub sektor pertanian yang dianggap menjadi basis komoditi Kabupaten Pasaman. Hal ini sejalan dengan kebij Surat Keputusan Bupati Pasaman Tahun 2007 tentang Penetapan Kawasan Agropolitan Kabupaten Pasaman dan Rencana Tata Ruang Wilayah (RTRW) Kabupaten Pasaman Tahun 2010-2030. Informasi mengenai penelitian ini dapat dijadikan bahan 
pertimbangan bagi pemerintah daerah dalam menetukan rencana dan kebijakan pembangunan, sehingga pembangunan di Kabupaten Pasaman berjalan lebih efisien.

\section{METODE PENELITIAN}

Wilayah yang menjadi objek penelitian adalah Kabupaten Pasaman meliputi 12 kecamatan. Kabupaten Pasaman dipilih secara purposive dikarenakan Kabupaten Pasaman tergolong daerah relatif tertinggal. Dimana laju pertumbuhan PDRB Kabupaten Pasaman lebih kecil dibanding rata-rata kabupaten di Sumatera Barat serta memiliki PDRB perkapita lebih rendah dibanding rata-rata Kabupaten di Sumatera Barat. Metode penelitian yang digunakan dalam penelitian ini bersifat deskriptif kuantitatif. Data yang dikumpulkan dalam penelitian ini terdiri dari data sekunder. Data penelitian ini diperoleh dari Badan Pusat Statistik Sumatera Barat, Badan Pusat Statistik Kabupaten Pasaman dan Dinas Pertanian Kabupaten Pasaman.

Adapun variabel yang diamati diklasifikasikan menjadi tiga jenis. Variabel Pertama adalah untuk mengidentifikasi pusat-pusat pertumbuhan di Kabupaten Pasaman, meliputi : fungsi fasilitas sosial (fasilitas kesehatan, fasilitas pendidikan, dan fasilitas peribadatan), fungsi fasilitas pemerintahan (fasilitas kantor camat, desa/kelurahan), dan fungsi fasilitas ekonomi (fasilitas pasar, fasilitas sarana angkutan, fasiltas industri, fasilitas tempat wisata, koperasi simpan pinjam, koperasi KUD, koperasi serba usaha, koperasi pertanian dan sebagainya. Variabel kedua untuk mengetahui komoditi pertanian basis di Kabupaten Pasaman, meliputi : nilai produksi perkomoditi pertanian di masing-masing kecamatan di Kabupaten Pasaman tahun 2016-2018, nilai produksi total komoditi pertanian di masing-masing kecamatan di Kabupaten Pasaman tahun 2016-2018, nilai produksi perkomoditi pertanian di Kabupaten Pasaman 2016-2018, nilai produksi total komoditi pertanian di Kabupaten Pasaman tahun 2016-2018. Variabel ketiga untuk mengidentifikasi interaksi antara pusat pertumbuhan dengan daerah sekitarnya, meliputi : jumlah Penduduk di Kabupaten Pasaman, jarak antar pusat pertumbuhan dengan daerah sekitarnya.

Penelitian ini menggunakan tiga metode analisis data, yaitu analisis Skalogram, Indeks Sentralitas, Location Quotient serta analisis Gravitasi. Analisis Skalogram dan Indeks Sentralitas digunakan untuk mengetahui pusat pertumbuhan ekonomi berdasarkan ketersediaan fasilitas umum yang dimiliki dengan menentukan hirarki wilayah. Sedangkan analisis Location Quotient digunakan untuk mengetahui komoditi pertanian basis di Kabupaten Pasaman. Analisis interaksi atau gravitasi digunakan untuk mengetahui seberapa besar interaksi antara kecamata pusat pertumbuhan dengan kecamatan pendukung (hinterland).

\section{HASIL DAN PEMBAHASAN}

\section{Pusat Pertumbuhan Kabupaten Pasaman}

Berdasarkan hasil analisis menggunakan analisis skalogram dan indeks sentralitas, terdapat empat kecamatan yang dapat dikategorikan sebagai pusat pertumbuhan atau secara hirarki keempat kecamatan tersebut mempunyai hirarki yang lebih tinggi dibanding kecamatan lainnya. Kecamatan tersebut secara berurutan adalah adalah Kecamatan Lubuk Sikaping menempati hirarki I, Kecamatan Rao Selatan menempati hirarki III, Kecamatan Panti menempati hirarki III, dan Kecamatan Tigo Nagari menempati hirarki III. Sedangkan kecamatan lainnya menempati hirarki IV dan V. Hal ini menandakan ketersediaan jumlah dan jenis fasilitas empat kecamatan tersebut lebih banyak dibandingkan dengan kecamatan lainnya di Kabupaten Pasaman. Berikut tabel 9 menampilkan hasil perhitungan indeks sentralitas masing-masing Kecamatan di Kabupaten Pasaman. 
Tabel 1. Hirarki Wilayah Kecamatan Menurut Indeks Sentralitas di Kabupaten Pasaman Tahun 2018

\begin{tabular}{lllll}
\hline No & Kecamatan & $\begin{array}{l}\text { Jumlah Fungsi } \\
\text { Fasilitas }\end{array}$ & Indeks Sentralitas & Hirarki \\
\hline 1 & Tigo Nagari & 193 & 294.735 & III \\
2 & Bonjol & 187 & 239.141 & IV \\
3 & Simpang Alahan Mati & 101 & 144.806 & V \\
4 & Lubuk Sikaping & 186 & 572.491 & I \\
5 & Dua Koto & 226 & 221.268 & IV \\
6 & Panti & 221 & 320.986 & III \\
7 & Padang Gelugur & 319 & 219.665 & IV \\
8 & Rao & 192 & 207.373 & IV \\
9 & Rao Utara & 186 & 75.303 & V \\
10 & Rao Selatan & 273 & 324.169 & III \\
11 & Mapat Tunggul & 96 & 93.509 & V \\
12 & Mapat TunggulSelatan & 96 & 86.547 & V \\
\hline
\end{tabular}

\section{Komoditi Pertanian Basis di Kabupaten Pasaman}

Kecamatan Tigo Nagari memiliki komoditi basis berupa jagung, pisang, nenas, alpokat, mangga,durian, cabe, kacang panjang, bayam, kelapa sawit, ayam buras, sapi potong, kerbau, kambing, ikan sawah, ikan budidaya perairan umum, dan ikan sungai. Kecamatan Bonjol memiliki komiditi basis berupa padi sawah, ubi kayu, ubi jalar, nena, mangga, durian, jambu biji, cabe, ketimun, terung, kacang panjang, bayam, buncis, kangkung, karet, kulit manis, kakao, nilam, gardamunggu, pinang, ayam buras, itik, kelinci, ikan sawah, ikan budidaya perairan umum, dan ikan sungai. Kecamatan Simpang Alahan Mati memiliki komoditi basis barupa padi sawah, ubi kayu, ubi jalar, kacang tanah, kacang kedelai, kacang hijau, pisang, nenas, rambutan, duku, cabe, terung, kacang panjang, bayam, kangkung, karet, kulit manis, kakao, nilam, gardamunggu, ayam buras, itik, ikan sawah, ikan budidaya perairan umum, dan ikan sungai. Kecamatan Lubuk Sikaping memiliki komoditi basi s berupa padi sawah, ubi kayu, ubi jalar, kacang tanah, kacang hijau, pisang, salak, pepaya, alpokat, kelapa, kopi, kulit manis, kakao, gardamunggu, pinang, ayam ras petelur, ayam ras pedaging, kuda, ikan sawah, ikan budidaya perairan umum, dan ikan sungai. Komoditi basis Kecamatan Dua Koto adalah padi sawah, padi ladang, ubi kayu, ubi jalar, kacang tanah, kacang kedelai, pisang, jeruk, cabe, ketimun, terung, kacang panjang, bayam, buncis, kangkung, kelapa, karet, kopi, kulit manis, nilam, gardamunggu, enau, pinang, itik, sapi potong, kerbau, kambing, domba, kelinci, ikan sawah, ikan budidaya perairan umum, dan ikan sungai. Kecamatan Panti memiliki komoditi basis berupa padi sawah, kacang hijau, jeruk, mangga, rambutan, semangka, kelapa, kulit manis, kakao, nilam, gardamunggu, kelapa sawit, gambir, itik, sapi potong, kerbau, kambing, kelinci, dan ikan kolam. Kecamatan Padang Gelugur memiliki komoditi basis berupa padi sawah, mangga, rambutan, duku, jambu biji, kopi, kakao, enau, pinang, itik, dan ikan kolam. Kecamatan Rao memiliki komoditi basis berupa padi sawah, alpokat, mangga, duku, jambu biji, ketimun, terung, kacang panjang, buncis, kelapa, kopi, kelapa sawit, enau, ayam buras, itik, dan ikan kolam. Kecamatan Rao Utara memiliki komoditi pertanian basis berupa padi sawah, pisang, rambutan, duku, durian, cabe, kelapa, karet, kopi, kulit manis, enau, pinang, kemiri, ayam buras, kerbau, kambing, kelinci, ikan budidaya perairan umum, dan ikan sungai. Kecamatan Rao Sealatan memiliki komoditi basis berupa padi sawah, nenas, alpokat, mangga, duku, cabe, ketimun, terung, kacang panjang, bayam, buncis, kangkung, kelapa, kopi, kakao, enau, ayam ras pedaging, kerbau, kambing, domba, dan ikan kolam. Kecamatan Mapat Tunggul memiliki komoditi pertanian basis berupa 
padi ladang, jagung, ubi kayu, kacang tanah, kacang kedelai, kacang hijau, pisang, pepaya, mangga, durian, ketimun, terung,kacang panjang, buncis, karet, nilam, kemiri, gambir, ayam buras, ayam ras petelur, kuda, kambing, ikan budidaya perairan umum, dan ikan sungai. Terakhir Kecamatan Mapat Tunggul Selatan memiliki komoditi basis berupa padi ladang, ubi kayu, ubi jalar, kacang tanah, kacang kedelai, kacang hijau, nenas, jeruk, mangga, duku, jambu biji, cabe, ketimun, terung, kacang panjang, buncis, karet, nilam, gambir, ayam buras,kambing, ikan budidaya perairan umum, dan ikan sungai. memiliki angka interaksi tertinggi dengan Kecamatan Lubuk Sikaping yaitu 1.259.489,457 dan angka interaksi tertinggi kedua dengan Kecamatan Simpang Alahan Mati yaitu 1.240.248,188.

\section{KESIMPULAN}

Berdasarkan hasil analisis skalogram dan indeks sentralitas didapatkan bahwa dari 12 kecamatan yang ada di Kabupaten Pasaman, teridentifikasi sebanyak 4 kecamatan sebagai pusat pertumbuhan yaitu Kecamatan Lubuk Sikaping, Kecamatan Rao Selatan, Kecamatan Panti dan Kecamatan Tigo Nagari. Berdasarkan hasil analisis interaksi/gravitasi

Tabel 2. Hasil Interaksi Kecamatan Pusat Pertumbuhan dengan Dua Kecamatan Hinterland

\begin{tabular}{|c|c|c|c|}
\hline$\overline{\text { No }}$ & Kecamatan Pusat Pertumbuhan & Kecamatan Hinterland & Nilai Interaksi \\
\hline \multirow[b]{2}{*}{1} & & Bonjol & 4868478.16 \\
\hline & Lubuk Sikaping & Panti & 3659894.57 \\
\hline \multirow[b]{2}{*}{2} & & Rao & 8663559.69 \\
\hline & Rao Selatan & Padang Gelugur & 2819332.65 \\
\hline \multirow{3}{*}{3} & & Lubuk Sikaping & 3659894.57 \\
\hline & Panti & Padang Gelugur & 1936826.03 \\
\hline & & Lubuk Sikaping & 1259489.46 \\
\hline 4 & Tigo Nagari & Simpang Ala han Mati & 1240248.19 \\
\hline
\end{tabular}

\section{Analisis Interaksi}

Masing-masing kecamatan pusat pertumbuhan mempunyai satu kecamatan hinterland utama. Hal ini dilihat dari angka interaksi tertinggi. Kecamatan Lubuk Sikaping memiliki angka interaksi paling tinggi terhadap Kecamatan Bonjol dengan nilai interaksi 4868478,164. Sedangkan Rao Selatan sebagai kecamatan pusat pertumbuhan, memiliki nilai interaksi tertinggi terhadap Kecamatan Rao yaitu 8.663.559,688. Kemudian Kecamatan Panti sebagai kecamatan pusat pertumbuhan memiliki interaksi tertinggi terhadap Kecamatan Lubuk Sikaping yaitu 3659894,566 dan nilai interaksi tertinggi kedua terhadap Kecamatan Padang Gelugur yaitu 1936826,033. Terakhir Kecamatan Tigo Nagari dengan menggunakan data jumlah penduduk tiap kecamatan dan jarak antar kecamatan, kecamatan pusat pertumbuhan Lubuk Sikaping memiliki hubungan interaksi yang paling erat dengan Kecamatan Bonjol sebagai daerah sekitarnya (hinterlandnya), Rao Selatan memiliki hubungan interaksi yang paling erat dengan Kecamatan Rao sebagai daerah sekitarnya (hinterland-nya). Panti memiliki hubungan interaksi yang paling erat dengan Kecamatan Lubuk Sikaping dan Kecamatan Padang Gelugur sebagai daerah sekitarnya (hinterland-nya). Kecamatan pusat pertumbuhan Tigo Nagari memiliki hubungan interaksi paling erat dengan Kecamatan Lubuk Sikaping dan Kecamatan Simpang Alahan Mati sebagai daerah sekitarnya (hinterland-nya). 


\section{UCAPAN TERIMA KASIH}

Ucapan terima kasih ditujukan kepada pembimbing Dosen Agribisnis Fakultas Pertanian Universitas Andalas yang telah membimbing selama penelitian.

\section{Daftar Pustaka}

BPS Pasaman. (2019). Kabupaten Pasaman dalamAngka. Pasaman.

Miyarto, Widyarti, \& Sugiyanto. (1993). Studi Antar Sektor Ekonomi Dalam Kaitannya Dengan Usaha Peningkatan Kesempatan Kerja di Indonesia. Prosiding Seminar Nasional Hasil Penelitian Perguruan Tinggi, Departemen Pendidikan dan Kebudayaan.

Syafrizal. (2008). Ekonomi Regional Teori dan Aplikasi . Padang: Baduose Media.

Todaro. (2009). Pembangunan Ekonomi di Dunia Ketiga. Jakarta (ID): Erlangga. 